\title{
Association of sleep quality and sleep duration with estimated Glomerular filtration rate冈eGFR囚in a secondary analysis based on a cross-sectional study
}

\author{
Wei Cao ( $\nabla$ caow0120@163.com ) \\ Huangshi Central Hospital, Affiliated Hospital of Hubei Polytechnic University \\ Ruixiang Cen \\ Huangshi Central Hospital, Affiliated Hospital of Hubei Polytechnic University \\ Yandan Chen \\ Huangshi Central Hospital, Affiliated Hospital of Hubei Polytechnic University
}

\section{Research Article}

Keywords: Sleep quality, sleep duration, estimated glomerular filtration rate

Posted Date: January 27th, 2022

DOI: https://doi.org/10.21203/rs.3.rs-1280104/v1

License: (c) (1) This work is licensed under a Creative Commons Attribution 4.0 International License.

Read Full License 


\section{Abstract}

Background: Poor sleep conditions can cause many diseases. However, proof regarding the link of sleep status with renal function in general population is limited. This study was undertaken to investigate the association of sleep quality and sleep duration with estimated Glomerular filtration rate『eGFR囚in Taiwanese participants.

Methods: The present study was a cross-sectional study. 5714 Taiwanese who visited a health center for a self-motivated general health assessment were collected in this study. The main outcome variables included Pittsburgh Sleep Quality Index囚PSQIखand Self-reported sleep duration. The Independent variable is estimated glomerular filtration rate (eGFR). Multivariate linear regression model and two-piecewise linear model are employed to examine the association between outcomes and independent variables after adjusting for covariates involved in this study.

Results: After adjusting potential confounders, a non-linear relationship was detected between sleep quality and eGFR, which cut-point was 71 . The effect sizes and the $95 \%$ confidence intervals on the right sides of inflection point were $0.982(0.967,0.998)$ and1.006 $(1.001,1.010)$.

Conclusion: The relationship between sleep quality and eGFR is non-linear. Sleep quality was negatively related to eGFR when eGFR is higher than 71points.

\section{Introduction}

Sleep plays an important role in maintaining personal health ${ }^{1}$. However, in today's society, short sleep duration, poor sleep quality, and even insomnia are common ${ }^{2}$. Existing evidence has shown that short sleep duration or poor sleep quality is closely related to cardiovascular disease, obesity, hypertension, non-alcoholic liver disease, diabetes (DM), dyslipidemia, and even death ${ }^{3,4}$. This suggests that sleep duration and quality may be a new and modifiable target for the treatment and prevention of various chronic diseases.

There are many evaluation indicators of renal function, including traditional indicators just as a bun, $\mathrm{Cr}$, and so on. However, the most com indicator used in clinical is estimated glomerular filtration rate (eGFR) ${ }^{5}$. Previous studies have shown that sleep status (quality and length) is related to eGFR in Chronic kidney disease (CKD) patients ${ }^{6}$, but in the general population, evidence regarding eGFR and sleep status is limited. Therefore, we performed a secondary analysis based on a published dataset to investigate the true relationship between sleep status and eGFR in Taiwanese adults. If the true relationship in the general population is found, it will help doctors provide more health advice to medical examiners, and provide supporting pilot data for subsequent cascading studies.

\section{Participants And Methods}




\section{Methods}

\section{Data source}

We extracted data from the 'DATADRYAD' database(www. Datadryad.org). Given the data, uploader has waived all copyright, therefore, a secondary analysis without infringing on the authors' rights. When data were used, Dryad data package (Dryad data package: Yu-Tsung Chou, Chung-Hao Li, Wei-Chen Shen, YiChing Yang, FengHwa Lu, Jin-Shang Wu, Chih-Jen Chang (2020). Data from: Association of sleep quality and sleep duration with serum uric acid levels in adults. PLoS

ONE. https://doi.org/10.1371/journal.pone.0239185) was noted. Variables included in the database file were listed as follows: age, sex, alanine aminotransferase (ALT), systolic blood pressure (SBP), fasting blood glucose(FBG), diastolic blood pressure (DBP), hypertension, body mass index (BMI), uric acid, triglyceride(TG), total cholesterol (TC), high-density lipoprotein cholesterol (HDL-C), eGFR, smoking status, exercise status, diabetes, alcohol consumption, use of uric acid lowering drug, use of hypoglycemic drugs, use of antihypertensive drug, use of lipid-lowering drugs, Pittsburgh Sleep Quality Index (PSQI) and Self-reported sleep duration.

\section{Study population}

Yu-Tsung Chou et al. ${ }^{7}$ completed the entire study, and we just outlined the steps of the study here. More details have been described in the original literature. Yu-Tsung Chou et al.conducted a cross-sectional study at a health examination center at National Cheng Kung University Hospital in Tainan city, Taiwan from October 2001 to August 2009. A total of 5714 participants were recruited and selected according to exclusion standards. Exclusion standards: (1) participants were aged <18 years, (2) participants on medications for hyperuricemia, hypertension, DM, or dyslipidemia;(3) those with incomplete data were excluded. Researchers obtained information (values) of PSQI, Self-reported sleep duration, eGFR, and other covariants at baseline. In the previously published article, Yu-Tsung Chou, et al. has clearly stated that: the study was conducted by the Declaration of Helsinki. Informed consent was obtained from all participants.

\section{Measurement of PSQI, Self-reported sleep duration, eGFR, and other covariants}

Sleep duration and quality were assessed using the Chinese version of the PSQI, Participants with a PSQI score of $>5$ were defined as poor sleepers. The eGFR was calculated by using the Chronic Kidney Disease Epidemiology Collaboration (CKD-EPI) equation. The measurement and assessment of PSQI and other covariants were described in detail in the original. 


\section{Statistical analysis}

Continuous variables are represented by median (quartile) (skew distribution) or mean \pm standard deviation (normal distribution), and categorical variables are represented by frequency or percentage. The differences between the mean and proportion of the groups were analyzed by Kruskal Whallis $\mathrm{H}$ (skew distribution) test, one-way analysis of variance (normal distribution), and chi-square test (categorical variable). (For outcome=sleep time) and binary logistic regression (for outcome=sleep quality (PSQI $\leq 5$, PSQI>5) models are used for univariate and multiple linear analysis. According to the suggestion of STROBE statement, we also show unadjusted the result of the minimum adjustment and the adjustment in the fully adjusted model. Whether the covariances were adjusted determined by the following principle: when added to this model, changed the matched odds ratio by at least $10 \%^{8}$.

We also use the Generalized Additive Model (GAM) to solve nonlinear problems. First, we use a smoothing graph (penalty method) to fit the relationship between eGFR and sleep status. Second, if a non-linear correlation was observed, we use a recursive method to automatically calculate the inflection point that will use the maximum model likelihood ${ }^{9}$. Third, to further explain the nonlinearity, we use a twopart linear model to fit the size of the effect on both sides of the inflection point. All analyses used statistical software packages R (http://www.R-project.org, R Foundation) and EmpowerStats (http://www.empowerstats.com, X\&Y Solutions, Inc., Boston, Massachusetts). A P value of less than 0.05 (two-sided) is considered statistically significant.

\section{Results}

\section{Baseline characteristics of participants}

Baseline characteristics were listed in Table 1. In terms of self-reported sleep duration, no statistically significant differences are detected among different eGFR groups. Compared with high level (Q4) of eGFR group, participants are older in Q1, Q2, and Q3 groups. In addition, higher levels of ALT, SBP, FBG, uric acid, DBP, BMI, TC, TG, and HDL-C are observed in Q1, Q2, and Q3 eGFR groups compared with Q4 group.

\section{Table 1}

Baseline Characteristics of participants 


\begin{tabular}{|c|c|c|c|c|c|}
\hline eGFR & Q1 & Q2 & Q3 & Q4 & P-value \\
\hline $\mathrm{N}$ & 1427 & 1423 & 1435 & 1429 & \\
\hline Age, mean $\pm S D$, year & $\begin{array}{l}52.07 \pm \\
10.95\end{array}$ & $\begin{array}{l}47.38 \pm \\
13.54\end{array}$ & $\begin{array}{l}46.35 \pm \\
9.61\end{array}$ & $\begin{array}{l}36.92 \pm \\
8.53\end{array}$ & $<0.001$ \\
\hline ALT, median $ه P 25, P 75 \rrbracket, U / L$ & $\begin{array}{l}28.00 \\
\rrbracket 21.00 \rrbracket \\
40.00 \rrbracket\end{array}$ & $\begin{array}{l}26.00 \\
\rrbracket 19.00 \rrbracket \\
38.00 \rrbracket\end{array}$ & $\begin{array}{l}26.00 \\
\rrbracket 18.00 \rrbracket \\
39.00 \rrbracket\end{array}$ & $\begin{array}{l}19.00 \\
\rrbracket 13.00 \rrbracket \\
28.00 \rrbracket\end{array}$ & $<0.001^{*}$ \\
\hline SBP, mean $\pm S D, m m H g$ & $\begin{array}{l}121.41 \pm \\
16.69\end{array}$ & $\begin{array}{l}118.62 \pm \\
16.38\end{array}$ & $\begin{array}{l}116.52 \pm \\
16.05\end{array}$ & $\begin{array}{l}108.44 \pm \\
13.58\end{array}$ & $<0.001$ \\
\hline FBG, mean $\pm S D, m g / d L$ & $\begin{array}{l}94.52 \pm \\
20.57\end{array}$ & $\begin{array}{l}93.62 \pm \\
24.58\end{array}$ & $\begin{array}{l}93.55 \pm \\
27.14\end{array}$ & $\begin{array}{l}88.93 \pm \\
23.69\end{array}$ & $<0.001$ \\
\hline uric acid, mean $\pm S D, m g / d L$ & $7.11 \pm 1.45$ & $6.26 \pm 1.39$ & $5.82 \pm 1.33$ & $5.14 \pm 1.33$ & $<0.001$ \\
\hline $\mathrm{DBP}$, mean $\pm \mathrm{SD}, \mathrm{mmHg}$ & $\begin{array}{l}73.41 \pm \\
10.71\end{array}$ & $\begin{array}{l}70.29 \pm \\
24.58\end{array}$ & $\begin{array}{l}68.91 \pm \\
10.35\end{array}$ & $\begin{array}{l}63.27 \pm \\
9.07\end{array}$ & $<0.001$ \\
\hline $\begin{array}{l}\text { body mass index, } \\
\text { mean } \pm S D, \mathrm{~kg} / \mathrm{m}^{2}\end{array}$ & $\begin{array}{l}25.24 \pm \\
3.06\end{array}$ & $\begin{array}{l}24.47 \pm \\
3.35\end{array}$ & $\begin{array}{l}24.10 \pm \\
3.33\end{array}$ & $\begin{array}{l}23.01 \pm \\
3.99\end{array}$ & $<0.001$ \\
\hline $\mathrm{TC}$, mean $\pm \mathrm{SD}, \mathrm{mg} / \mathrm{dL}$ & $\begin{array}{l}201.40 \pm \\
36.04\end{array}$ & $\begin{array}{l}199.46 \pm \\
36.50\end{array}$ & $\begin{array}{l}197.73 \pm \\
36.73\end{array}$ & $\begin{array}{l}182.73 \pm \\
34.81\end{array}$ & $<0.001$ \\
\hline $\mathrm{TG}$, mean $\pm \mathrm{SD}, \mathrm{mg} / \mathrm{dL}$ & $\begin{array}{l}150.13 \pm \\
97.32\end{array}$ & $\begin{array}{l}132.70 \pm \\
80.62\end{array}$ & $\begin{array}{l}132.28 \pm \\
101.09\end{array}$ & $\begin{array}{l}104.65 \pm \\
80.42\end{array}$ & $<0.001$ \\
\hline $\mathrm{HDL}-\mathrm{C}$, mean $\pm \mathrm{SD}, \mathrm{mg} / \mathrm{dL}$ & $\begin{array}{l}44.59 \pm \\
11.18\end{array}$ & $\begin{array}{l}48.33 \pm \\
13.02\end{array}$ & $\begin{array}{l}49.51 \pm \\
14.15\end{array}$ & $\begin{array}{l}53.44 \pm \\
13.77\end{array}$ & $<0.001$ \\
\hline $\begin{array}{l}\text { Self-reported sleep duration, } \\
\text { mean } \pm S D, h / \text { day }\end{array}$ & $6.42 \pm 1.11$ & $6.51 \pm 1.12$ & $6.46 \pm 1.04$ & $6.53 \pm 1.17$ & 0.059 \\
\hline $\operatorname{Sex}(n, \%)$ & & & & & $<0.001$ \\
\hline female & $53(3.71 \%)$ & $\begin{array}{l}418 \\
(29.37 \%)\end{array}$ & $\begin{array}{l}627 \\
(43.69 \%)\end{array}$ & $\begin{array}{l}1113 \\
(77.89 \%)\end{array}$ & \\
\hline male & $\begin{array}{l}1374 \\
(96.29 \%)\end{array}$ & $\begin{array}{l}1005 \\
(70.63 \%)\end{array}$ & $\begin{array}{l}808 \\
(56.31 \%)\end{array}$ & $\begin{array}{l}316 \\
(22.11 \%)\end{array}$ & \\
\hline $\begin{array}{l}\text { Uric acid-lowering drug use } \\
(\mathrm{n}, \%)\end{array}$ & & & & & $<0.001$ \\
\hline No & $\begin{array}{l}1228 \\
(86.05 \%)\end{array}$ & $\begin{array}{l}1334 \\
(93.75 \%)\end{array}$ & $\begin{array}{l}1357 \\
(94.56 \%)\end{array}$ & $\begin{array}{l}1414 \\
(98.95 \%)\end{array}$ & \\
\hline Yes & $\begin{array}{l}199 \\
(13.95 \%)\end{array}$ & $89(6.25 \%)$ & $78(5.44 \%)$ & $15(1.05 \%)$ & \\
\hline DM $(n, \%)$ & & & & & $<0.001$ \\
\hline No & $\begin{array}{l}1309 \\
(91.73 \%)\end{array}$ & $\begin{array}{l}1328 \\
(93.32 \%)\end{array}$ & $\begin{array}{l}1336 \\
(93.10 \%)\end{array}$ & $\begin{array}{l}1383 \\
(96.78 \%)\end{array}$ & \\
\hline
\end{tabular}




\begin{tabular}{|c|c|c|c|c|c|}
\hline Yes & $118(8.27 \%)$ & 95 (6.68\%) & 99 (6.90\%) & 46 (3.22\%) & \\
\hline Smoking status $(\mathrm{n}, \%)$ & & & & & $<0.001$ \\
\hline No & $\begin{array}{l}1131 \\
(79.26 \%)\end{array}$ & $\begin{array}{l}1160 \\
(81.52 \%)\end{array}$ & $\begin{array}{l}1181 \\
(82.30 \%)\end{array}$ & $\begin{array}{l}1298 \\
(90.83 \%)\end{array}$ & \\
\hline Yes & $\begin{array}{l}296 \\
(20.74 \%)\end{array}$ & $\begin{array}{l}263 \\
(18.48 \%)\end{array}$ & $\begin{array}{l}254 \\
(17.70 \%)\end{array}$ & $131(9.17 \%)$ & \\
\hline $\begin{array}{l}\text { Alcoholic consumption ( } \mathrm{n}, \\
\% \text { ) }\end{array}$ & & & & & $<0.001$ \\
\hline No & $\begin{array}{l}1088 \\
(76.24 \%)\end{array}$ & $\begin{array}{l}1175 \\
(82.57 \%)\end{array}$ & $\begin{array}{l}1196 \\
(83.34 \%)\end{array}$ & $\begin{array}{l}1281 \\
(89.64 \%)\end{array}$ & \\
\hline Yes & $\begin{array}{l}339 \\
(23.76 \%)\end{array}$ & $\begin{array}{l}248 \\
(17.43 \%)\end{array}$ & $\begin{array}{l}239 \\
(16.66 \%)\end{array}$ & $\begin{array}{l}148 \\
(10.36 \%)\end{array}$ & \\
\hline Hypertension (n, \%) & & & & & $<0.001$ \\
\hline No & $\begin{array}{l}1036 \\
(72.60 \%)\end{array}$ & $\begin{array}{l}1139 \\
(80.04 \%)\end{array}$ & $\begin{array}{l}1203 \\
(83.83 \%)\end{array}$ & $\begin{array}{l}1355 \\
(94.82 \%)\end{array}$ & \\
\hline Yes & $\begin{array}{l}391 \\
(27.40 \%)\end{array}$ & $\begin{array}{l}284 \\
(19.96 \%)\end{array}$ & $\begin{array}{l}232 \\
(16.17 \%)\end{array}$ & 74 (5.18\%) & \\
\hline Exercise > 3/wk $(n, \%)$ & & & & & $<0.001$ \\
\hline No & $\begin{array}{l}1182 \\
(82.83 \%)\end{array}$ & $\begin{array}{l}1226 \\
(86.16 \%)\end{array}$ & $\begin{array}{l}1243 \\
(86.62 \%)\end{array}$ & $\begin{array}{l}1333 \\
(93.28 \%)\end{array}$ & \\
\hline Yes & $\begin{array}{l}245 \\
(17.17 \%)\end{array}$ & $\begin{array}{l}197 \\
(13.84 \%)\end{array}$ & $\begin{array}{l}192 \\
(13.38 \%)\end{array}$ & $96(6.72 \%)$ & \\
\hline $\begin{array}{l}\text { Use of hypoglycemic drugs } \\
(n, \%)\end{array}$ & & & & & $<0.001$ \\
\hline No & $\begin{array}{l}1358 \\
(95.16 \%)\end{array}$ & $\begin{array}{l}1367 \\
(96.06 \%)\end{array}$ & $\begin{array}{l}1389 \\
(96.79 \%)\end{array}$ & $\begin{array}{l}1410 \\
(98.67 \%)\end{array}$ & \\
\hline Yes & $69(4.84 \%)$ & $56(3.94 \%)$ & $46(3.21 \%)$ & $19(1.33 \%)$ & \\
\hline $\begin{array}{l}\text { Antihypertensive drug use } \\
(\mathrm{n}, \%)\end{array}$ & & & & & $<0.001$ \\
\hline No & $\begin{array}{l}1219 \\
(85.42 \%)\end{array}$ & $\begin{array}{l}1269 \\
(89.18 \%)\end{array}$ & $\begin{array}{l}1324 \\
(92.26 \%)\end{array}$ & $\begin{array}{l}1400 \\
(97.97 \%)\end{array}$ & \\
\hline Yes & $\begin{array}{l}208 \\
(14.58 \%)\end{array}$ & $\begin{array}{l}154 \\
(10.82 \%)\end{array}$ & $111(7.74 \%)$ & 29 (2.03\%) & \\
\hline $\begin{array}{l}\text { Use of lipid-lowering drugs } \\
(\mathrm{n}, \%)\end{array}$ & & & & & $<0.001$ \\
\hline No & $\begin{array}{l}1290 \\
(90.40 \%)\end{array}$ & $\begin{array}{l}1333 \\
(93.68 \%)\end{array}$ & $\begin{array}{l}1344 \\
(93.66 \%)\end{array}$ & $\begin{array}{l}1403 \\
(98.18 \%)\end{array}$ & \\
\hline
\end{tabular}




\begin{tabular}{|llllll|} 
Yes & $137(9.60 \%)$ & $90(6.32 \%)$ & $91(6.34 \%)$ & $26(1.82 \%)$ & \\
PSQI & & & & $<0.001$ \\
\hline$\leq 5$ & 599 & 584 & 541 & 463 \\
& $(42.21 \%)$ & $(41.30 \%)$ & $(38.10 \%)$ & $(32.58 \%)$ & \\
\hline 55 & 820 & 830 & 879 & 958 \\
& $(57.79 \%)$ & $(58.70 \%)$ & $(61.90 \%)$ & $(67.42 \%)$ & \\
\hline
\end{tabular}

ALT alanine aminotransferase, SBP systolic blood pressure, FBG fasting blood glucose, DBP diastolic blood pressure, hypertension, BMI body mass index, uric acid, triglyceride(TG), total cholesterol (TC), highdensity lipoprotein cholesterol (HDL-C), estimated glomerular filtration rate (eGFR) $\square$ Pittsburgh Sleep Quality Index(PSQI),

\section{The univariate and multivariate results of relationship between sleep status and eGFR}

We showed the non-adjusted and adjusted models in Table 2.

For sleep quality $\mathbb{}$ a result obtained from crude model suggests that a unit increase of eGFR is associated with $1 \%$ increase of probability of good sleep quality $(\mathrm{OR}=1.006,95 \%$ confidence interval $(\mathrm{Cl}): 1.004$ to $1.009, P<0.0001)$. After adjusting for other confounders (Minimally- and Fully-adjusted models), however, we do not detect the association between sleep quality and eGFR.

Self-reported sleep duration showed no correlation with eGFR ( $\beta=-0.001,95 \%$ confidence interval $(\mathrm{Cl})$ : -0.003 to $0.001, P=0.2415$ ). In minimally adjusted model (adjusted age, sex), the result showed no correlation was detected $(\beta=0.001,95 \% \mathrm{Cl}:-0.002$ to $0.003, P=0.6057)$. The same findings also observed in fully-adjusted model.

For the purpose of sensitivity analyses, we also transformed eGFR from a continuous variable to a categorical variable according to quartile. The results of $\mathrm{P}$ for trend are consistent with eGFR as a continuous variable.

\section{Table 2}

Results of univariate and multivariate analysis 
Exposure

Non-adjusted model

Effect size, 95\%Cl, P-

value
Minimally-adjusted model Effect size, $95 \% \mathrm{Cl}, \mathrm{P}-\quad$ value value
Fully-adjusted model Effect size, 95\%Cl, P-

\section{Sleep Quality}

Index(PSQI $\leq 5, \varangle 5)$

\begin{tabular}{|c|c|c|c|}
\hline eGFR & $\begin{array}{l}1.006(1.004,1.009) \\
<0.0001\end{array}$ & $\begin{array}{l}1.002(0.999,1.006) \\
0.1467\end{array}$ & $\begin{array}{l}1.002(0.998,1.005) \\
0.3276\end{array}$ \\
\hline
\end{tabular}

eGFR(quartile)

\begin{tabular}{llll}
\hline Q1 & Ref & Ref & Ref \\
\hline Q2 & $1.038(0.894,1.205)$ & $0.972(0.831,1.137)$ & $0.966(0.822,1.134)$ \\
& 0.6228 & 0.7195 & 0.6718 \\
\hline Q3 & $1.187(1.021,1.379)$ & $1.079(0.915,1.273)$ & $1.054(0.888,1.252)$ \\
& 0.0254 & 0.3663 & 0.5454 \\
\hline Q4 & $1.511(1.297,1.761)$ & $1.238(1.003,1.528)$ & $1.184(0.950,1.476)$ \\
& $<0.0001$ & 0.0469 & 0.1323 \\
\hline P for trend & $<0.0001$ & 0.0341 & 0.1040 \\
\hline
\end{tabular}

Self-reported sleep duration

$\begin{array}{llll}\text { eGFR } & -0.001(-0.003,0.001) & 0.001(-0.002,0.003) & 0.001(-0.002,0.004) \\ & 0.2415 & 0.6057 & 0.4415\end{array}$

eGFR (quartile)

\begin{tabular}{clll} 
Q1 & Ref & Ref & Ref \\
\hline Q2 & $0.005(-0.121,0.131)$ & $0.042(-0.089,0.174)$ & $0.059(-0.075,0.193)$ \\
& 0.9425 & 0.5282 & 0.3866 \\
\hline Q3 & $-0.030(-0.156,0.096)$ & $0.044(-0.093,0.182)$ & $0.066(-0.076,0.208)$ \\
& 0.64103 & 0.52662 & 0.3622 \\
\hline Q4 & $-0.066(-0.191,0.060)$ & $0.027(-0.146,0.200)$ & $0.060(-0.120,0.240)$ \\
& 0.30713 & 0.7568 & 0.5152 \\
\hline P for trend & 0.0399 & 0.8861 & 0.9870
\end{tabular}

Non-adjusted model: we do not adjust for any covariates

Minimally-adjusted model: only sex and age are adjusted for.

Fully-adjusted model: all covariates presented in table 1 are adjusted for. 


\section{The analyses of non-linear relationship}

Nonlinearity addressing is necessary because eGFR is a continuous variable. In the present study (Fig. 1), By smooth curve fitting, we found that the relationship between sleep quality and eGFR was non-linear (after adjusting other covariants in Table 1), We calculated the inflection point was 71. On the left of inflection point, there is no relationship between eGFR and sleep quality (OR:0.989, 95\% $\mathrm{Cl} 0.977$ to 1.002 , $P=0.0907)$, respectively, we also observed a relationship between eGFR and sleep quality on the right of inflection point (OR:1.006, 95\% Cl 1.001 to1.01, $\mathrm{P}=0.0189$ ) (Table 3).PSQI scores of $>5$ were defined as poor sleepers, when eGFR is higher than 71points, the sleep quality decreases as the value of eGFR rises.

\section{Table 3}

nonlinearity of eGFR on sleeping quality

Outcome: $\quad$ PSQI $₫ \beta, 95 \%, P$-value区

Fitting model using standard linear regression $\quad 1.003(0.999,1.007) 0.1994$

Fitting model using two-piece wise linear model

\begin{tabular}{ll}
\hline Inflection point & 71 \\
\hline$\leq 71$ & $0.989(0.977,1.002) 0.0907$ \\
\hline$>71$ & $1.006(1.001,1.011) 0.0189$ \\
\hline P for Log-likelihood ratio test & 0.025
\end{tabular}

The adjustment strategy was the same as fully-adjusted model

\section{Discussion}

This study conducted a secondary data analysis based on a published cross-sectional study to predict and investigate the relationship between eGFR and sleep status. Although no linear relationship between eGFR and sleep state was observed. However, a nonlinear relationship between them was detected. Our results also found that eGFR is negatively correlated with sleep quality in the interval where the eGFR value is higher than 71 points. This result shows that within a certain range as eGRF increases, the sleep quality becomes worse. This result is similar to the study of Kim et al ${ }^{10}$. The results of Kim and our study indicate that excessive eGFR impairs sleep quality, which suggests that poor subjective sleep quality was associated with glomerular hyperfiltration in general population. The possible mechanism for the 
relationship between sleep quality and eGFR remains unclear. The common view is that poor sleep is considered part of normal aging. But a study showed that adult sleep quality is affected by age, selfreported sleep quality improves with age ${ }^{11}$. In addition, a previous study has pointed out that eGFR declines with aging ${ }^{12}$. Our research results found that sleep quality deteriorates as eGFR increases when eGFR is higher than 71 points(OR:1.006, 95\% $\mathrm{Cl} 1.001$ to1.01, $\mathrm{P}=0.0189)$, the normal value of EGFR was $80 \sim 120 \mathrm{ml} / \mathrm{min}$. The possible mechanism is that young adults have normal eGFR and poor sleep quality. In addition, poor sleep quality will exacerbate inflammation and oxidative stress ${ }^{13,14}$, and the exacerbation of inflammation and oxidative stress are associated with obesity and diabetes ${ }^{15}$. A previous study found that high eGFR is associated with early stages of kidney disease in the setting of various conditions such as obesity and diabetes ${ }^{16}$. Therefore, the sleep quality of patients in the early stage of kidney diseases deteriorates, and this may also be one of the reasons why the sleep quality deteriorates with the eGFR increase within a certain range in our study. Our research found that there is no relationship between eGFR and sleep quality when the eGFR value is lower than $71 \otimes O R: 0.989,95 \% \mathrm{Cl}$ 0.977 to1.002, $P=0.0907 \rrbracket$. This shows that sleep quality has not changed with the eGRF decline. This result is different from the study of Chang et al ${ }^{17}$. The study of Chang shows that good kidney function within a certain range has a positive effect on the improvement of sleep quality. The reason for the different results between the two studies may be that our study population is normal, while Chang's study population is CKD. Our research shows that sleep time has nothing to do with eGFR. This result is different from previous studies ${ }^{18}$. The population of other studies and data analysis methods is different from this study, and we speculate that this is the reason for the different results. The eGFR is an important indicator for evaluating renal function, the normal range of eGFR was $80 \sim 120 \mathrm{ml} / \mathrm{min}$, eGFR decreases in chronic kidney disease ${ }^{19}$, and increases in hypertensive diseases ${ }^{16}$. Our study found that high eGFR values cause a decline in sleep quality. This suggests that we should detect and intervene in the sleep quality of the patients with abnormal eGFR, to reduce the damage to the body caused by the decline in sleep quality. Our research found that the relationship between eGFR and sleep quality changes when the eGFR value is equal to 71. Since no previous studies have reported similar results, we cannot explain the specific reasons. However, this value can provide more health advice to medical examiners, and provide supporting pilot data for subsequent cascading studies. The methods and content of our research have some advantages. First, we not only use the generalized linear model to evaluate the linear relationship between sleep quality, sleep duration, and eGFR but also use the generalized additive model to clarify the nonlinear relationship. GAM has obvious advantages in dealing with nonlinear relationships. It can deal with non-parametric smoothing and fit regression splines to the data. The use of GAM will help us better discover the true relationship between exposure and results. Second, this study is an observational study that includes unavoidable potential confounders, so we use strict statistical adjustments to minimize residual confounders. Although previous studies have reported a relationship between sleep status and chronic kidney disease ${ }^{20,21}$, there are no studies on sleep quality and eGFR. In our research, we found the relationship between sleep quality and eGFR. There are still some limitations to our research. First of all, this study is an analytical cross-sectional study, so it only provides evidence between exposure and outcome, and the credibility of the evidence is weak, and the cause and outcome 
are difficult to distinguish. Secondly, because the study population only includes Chinese, it may not be able to improve references for other ethnic groups. Third, due to the limitation of the original data, we could not observe the correlation between the average night blood oxygen saturation and sleep quality and sleep duration, and eGFR. Similarly, we cannot study the level of hypoxia-inducible and inflammatory factors in plasma that reflect the body's hypoxia and its possible relationship with sleep status and eGFR.

\section{Conclusion}

The relationship between sleep quality and eGFR is non-linear. Sleep quality is negatively related to eGFR when eGFR was higher than 71.

\section{Declarations}

\section{Ethics approval and consent to participate}

In the previously published article ${ }^{7}$, Chou $\mathrm{YT}$, et al. has clearly stated that: the study was approved by the Institutional Review Board of National Health and Nutrition Examination Survey(NCKUH) in Taiwan (IRB number: A-ER-107-285). Informed consent was obtained from all participants.

\section{Consent for publication}

Not applicable.

\section{Availability of data and materials}

Data can be downloaded from 'DATADRYAD' database (www. Datadryad.org).

\section{Competing interests}

The authors declare no competing financial or non-financial interests.

\section{Funding}

Not applicable.

\section{Author's contributions}

RXC contributed to the drafting of the manuscript. CW, contributed to the conception and critical revision of the manuscript, analysis, and interpretation of the data, and YDC, contributed to approve the final 


\section{Acknowledgements}

The author is very grateful to the data providers of the study. They completed the entire study. They are (the rankings and institutions of these researchers were ranked according to the "reference 7") Yu-Tsung Chou, Chung-Hao Li, Wei-Chen Shen, Yi-Ching Yang, Feng- Hwa Lu, Jin-Shang Wu, Chih-Jen Chang (Department of Family Medicine, National Cheng Kung University Hospital, College of Medicine, National Cheng Kung University, Tainan, Taiwan).

\section{Author's information}

Department of Otorhinolaryngology, Huangshi Central Hospital, Affiliated Hospital of Hubei Polytechnic University, Edong Healthcare Group, No.141, Tianjin Road, Huangshi Port District, Huangshi 435000, HuangShi, China

\section{References}

1. Watson NF, Badr MS, Belenky G, et al. Recommended amount of sleep for a healthy adult: A joint consensus statement of the American Academy of Sleep Medicine and Sleep Research Society. Sleep. 2015;38(6):843-844. doi:10.5665/sleep.4716

2. Littlewood DL, Kyle SD, Carter LA, Peters S, Pratt D, Gooding P. Short sleep duration and poor sleep quality predict next-day suicidal ideation: An ecological momentary assessment study. Psychol Med. 2019;49(3):403-411. doi:10.1017/S0033291718001009

3. Lou P, Chen P, Zhang L, et al. Relation of sleep quality and sleep duration to type 2 diabetes: $A$ population-based cross-sectional survey. BMJ Open. 2012;2(4):6-10. doi:10.1136/bmjopen-2012000956

4. Buxton OM, Marcelli E. Short and long sleep are positively associated with obesity, diabetes, hypertension, and cardiovascular disease among adults in the United States. Soc Sci Med. 2010;71(5):1027-1036. doi:10.1016/j.socscimed.2010.05.041

5. Voldborg BR, Damstrup L, Poulsen HS. and Possible Role in Clinical Trials. Ann Oncol. 1997;(Figure 1):1197-1206.

6. Li J, Huang Z, Hou J, et al. Sleep and CKD in Chinese adults: A cross-sectional study. Clin J Am Soc Nephrol. 2017;12(6):885-892. doi:10.2215/CJN.09270816

7. Chou YT, Li CH, Shen WC, et al. Association of sleep quality and sleep duration with serum uric acid levels in adults. PLoS One. 2020;15(9 September 2020):1-13. doi:10.1371/journal.pone.0239185

8. England TN. Journal Medicine ( ). Published online 2000. 
9. Liu S, Wang X, Lu Y, et al. The effects of intraoperative cryoprecipitate transfusion on acute renal failure following orthotropic liver transplantation. Hepatol Int. 2013;7(3):901-909. doi:10.1007/s12072-013-9457-9

10. Kim CW, Chang Y, Sung E, et al. Sleep duration and quality in relation to chronic kidney disease and glomerular hyperfiltration in healthy men and women. PLoS One. 2017;12(4):1-15. doi:10.1371/journal.pone.0175298

11. Luca G, Haba Rubio J, Andries D, et al. Age and gender variations of sleep in subjects without sleep disorders. Ann Med. 2015;47(6):482-491. doi:10.3109/07853890.2015.1074271

12. Sun $X$, Chen $Y$, Chen $X$, et al. Change of glomerular filtration rate in healthy adults with aging. Nephrology. 2009;14(5):506-513. doi:10.1111/j.1440-1797.2009.01098.x

13. Petrov KK, Hayley A, Catchlove S, Savage K, Stough C. Is poor self-rated sleep quality associated with elevated systemic inflammation in healthy older adults? Mech Ageing Dev. 2020;192(May):111388. doi:10.1016/j.mad.2020.111388

14. Ntalapascha M, Makris D, Kyparos A, et al. Oxidative stress in patients with obstructive sleep apnea syndrome. Sleep Breath. 2013;17(2):549-555. doi:10.1007/s11325-012-0718-y

15. Karam BS, Chavez-Moreno A, Koh W, Akar JG, Akar FG. Oxidative stress and inflammation as central mediators of atrial fibrillation in obesity and diabetes. Cardiovasc Diabetol. 2017;16(1):17-20. doi:10.1186/s12933-017-0604-9

16. Kanbay M, Ertuglu LA, Afsar B, et al. Renal hyperfiltration defined by high estimated glomerular filtration rate: A risk factor for cardiovascular disease and mortality. Diabetes, Obes Metab. 2019;21(11):2368-2383. doi:10.1111/dom.13831

17. Chang W, Han Y, Song $X$, et al. Relationship between trajectory of sleep quality and short-term changes in residual renal function in stage 3-5 chronic kidney disease patients. Clin Exp Nephrol. 2020;24(6):557-564. doi:10.1007/s10157-020-01868-x

18. Guo X, Yu S, Li Z, et al. Self-reported sleep duration is associated with reduced glomerular filtration rate among adults with hypertension: A population-based study from rural northeast China. $J$ Sleep Res. 2015;24(3):351-358. doi:10.1111/jsr.12274

19. Rowe C, Sitch AJ, Barratt J, et al. Biological variation of measured and estimated glomerular filtration rate in patients with chronic kidney disease. Kidney Int. 2019;96(2):429-435. doi:10.1016/j.kint.2019.02.021

20. Bo Y, Yeoh E kiong, Guo C, et al. Sleep and the risk of chronic kidney disease: A cohort study. J Clin Sleep Med. 2019;15(3):393-400. doi:10.5664/jcsm.7660

21. Nakajima $\mathrm{H}$, Hashimoto $\mathrm{Y}, \mathrm{Okamura} \mathrm{T}$, et al. Association between Sleep Duration and Incident Chronic Kidney Disease: A Population-Based Cohort Analysis of the NAGALA Study. Kidney Blood Press Res. 2020;45(2):339-349. doi:10.1159/000504545

\section{Figures}




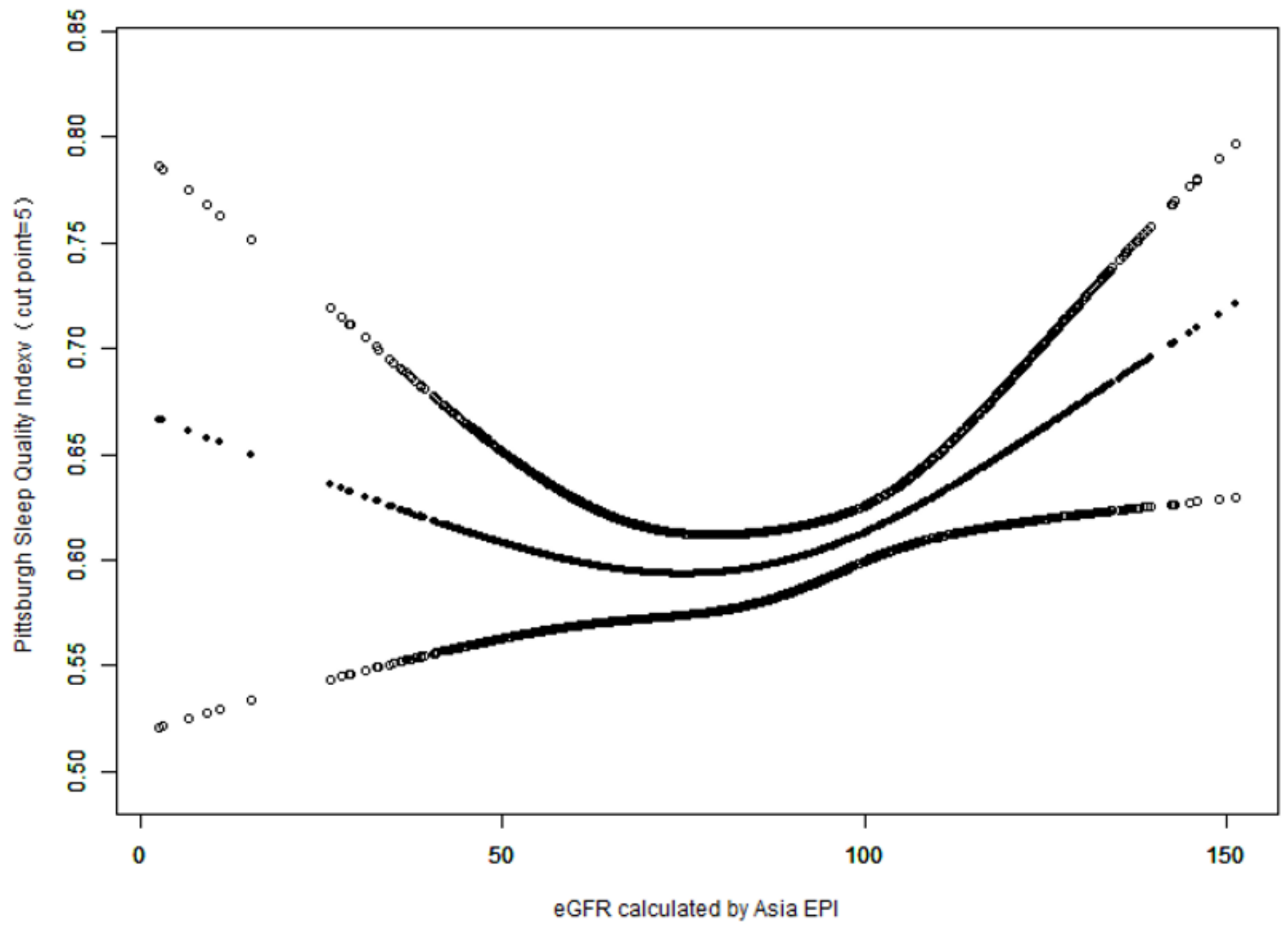

Figure 1

The relationship between PSQI and eGFR. A nonlinear relationship between them was detected after adjusting for other covariants in Table 1 